\title{
Guest editorial: introduction to the special issue on selected papers from the ELECO'2019 conference
}

\author{
S. Ozoguz ${ }^{1} \cdot$ O. Cicekoglu ${ }^{2}$ H. H. Kuntman ${ }^{1}$
}

Accepted: 1 March 2021 / Published online: 10 March 2021

(C) The Author(s), under exclusive licence to Springer Science+Business Media, LLC, part of Springer Nature 2021

Welcome to the Special Issue on Selected Papers from the ELECO-2019 Conference!, the eleventh international conference, with participants coming from various countries, presenting papers from the rich spectrum of electrical and electronics engineering.

ELECO conferences are traditionally organized at international level in odd numbered years and as national conferences in even numbered years. As such, ELECO 2019 is the eleventh international conference, with participants coming from various countries, presenting papers from the rich spectrum of electrical and electronics engineering. ELECO 2019 is jointly organized by Bursa Uludag University, Bursa; Istanbul Technical University (ITU), Istanbul and the Chamber of Turkish Electrical Engineers (EMO), Bursa Branch. The IEEE Turkey Section and The Scientific and Technological Research Council of Turkey are technical co-sponsors of ELECO 2019.

The scope of the conference covers topics ranging over energy sources, electric power systems, electrical machines and drives, power electronics, high voltage techniques, electrical materials, electronics, circuits and systems, signal processing, electromagnetics, antennas and propagation, microwave theory, communication systems, mechatronics, control theory, control applications, automation systems, robotics and intelligent control

O. Cicekoglu

cicekogl@boun.edu.tr

S. Ozoguz

ozoguz@itu.edu.tr

H. H. Kuntman

kuntman@itu.edu.tr

1 Faculty of Electrical Electronics Engineering, Istanbul Technical University, 34469 Maslak, Istanbul, Turkey

2 Electrical and Electronic Engineering Department, Bogazici University, 34342 Bebek, Istanbul, Turkey systems. The conference papers are the result of extensive analytical, experimental and computational works.

For ELECO 2019, 331 papers have been submitted for presentation and 224 papers have been accepted. Some of the accepted papers have been revised in the direction of the comments and remarks of the referees. The contributions are coming from 22 different countries.

Selected papers from international ELECO Conferences were invited to be published in extended form in special ELECO issues of international journals, under peer review.

This Special Issue on Selected Papers from ELECO'2019 contains extended versions of selected papers presented at the conference.

The paper by Ismail Çevik et al. entitled Transimpedance type MOS-C bandpass analog filter core circuits presents six area-efficient transimpedance type second-order analog filters.

The paper by Milan Stork entitled Using pulse width modulation with carrier frequency changing for transmission of two separate signals describes analog and digital circuits for modulation and demodulation of PWMF signals and measuring results are presented in the work.

The paper by Lida Kouhalvandi is entitled Optimization techniques for analog and RF circuit designs: an overview. The main purpose of this article is to provide a comprehensive and systematic literature review for the optimization approaches applied by the researchers for designing various analog and microwave circuits.

The paper by Lida Kouhalvandi et al. entitled Automated top-down pruning optimization approach in $\mathrm{RF}$ power amplifier designs presents an automated high-accuracy optimization approach for designing high-performance radio frequency high power amplifiers (HPAs).

The paper by Halil İbrahim Kayıhan et al. is entitled A wide-temperature range (77-400 K) CMOS low-dropout voltage regulator system. In this study, a low-dropout voltage regulator (LDO) system composed of two LDOs, 
which can operate in the temperature range of $77-400 \mathrm{~K}$, has been developed.

The paper by Engincan Tekin et al. is entitled Quantitative detection system for immunostrips in $180 \mathrm{~nm}$ standard CMOS technology. In this work, a CMOS based optical read-out system for biomarker on immunostrips detection is presented.

The paper by Fikret Başar Gencer et al. entitled Design and validation of an artificial neural network based on analog circuits focuses on the design and validation of an analog artificial neural network. Basic building blocks of the analog ANN have been constructed in UMC $90 \mathrm{~nm}$ device technology.

The paper by Didem Erol et al.entitled A switchable DC offset cancellation circuit for time-based degradation correction focuses on observing the aging impact of a DC offset cancellation circuit (DCOC) on the performance of an amplifier subject to time-based degradation.

The paper by Jaroslav Koton et al. entitled Designing Series of Fractional-Order Elements proposes an efficient approach to design fractional-order elements' (FOEs) series, while using a very limited set of "seed" FOEs.

The guest editors would like to thank Editor-in-Chief, Prof. Mohammed Ismail, for valuable supports and staff at Journals Editorial Office for their assistance in producing this volume. We hope you very much enjoy reading this special ELECO'2019 issue of Analog Integrated Circuits and Signal Processing.

Guest Editors of the Special Issue on Selected Papers from ELECO'2019.

Publisher's Note Springer Nature remains neutral with regard to jurisdictional claims in published maps and institutional affiliations.

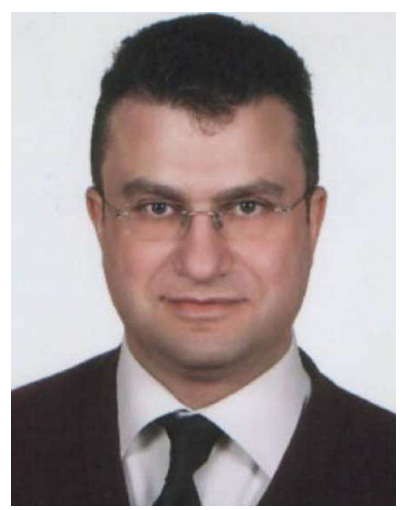

S. Ozoguz received his B.Sc., M.Sc. and Ph.D. degrees in Electronics Engineering from Istanbul Technical University in 1991, 1993 and 2000 respectively. Since 2009 , he is working as a full professor in Istanbul Technical University. His research interests include analog circuit design, chaotic circuits and chaos applications. Serdar Ozoguz has become a recipient of the Young Scientist Award of the Scientific and Technical Research Council of Turkey (TUBITAK) in 2004 and the Outstanding Young Scientist Award of the Turkish Academy of Sciences in 2002. He is the author or co-author of about 150 papers published in scientific journals or conference proceedings. Currently, he serves as the head of Electronics and Communication Engineering Department of Istanbul Technical University.

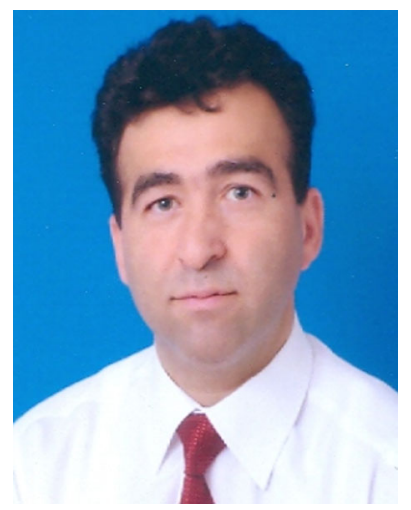

O. Cicekoglu received the B.Sc. and M.Sc. degrees from Bogazici University and the $\mathrm{PhD}$. degree from Istanbul Technical University all in Electrical and Electronics Engineering in 1985, 1988 and 1996, respectively. He joined Electrical and Electronics Engineering Department of the same University where he is currently a professor. Between 2007 and 2010, he was the Dean of Engineering at Corlu Engineering Faculty of Namik Kemal University, Turkey. During his period, four new undergraduate programs and several M.Sc. level programs are started. Between 2013 and 2016 he was the founding Dean of Engineering Faculty at Turkish-German University, Istanbul-Turkey. During his period, several new undergraduate engineering programs were established. Oguzhan Cicekoglu served in organizing and technical committees of many national and international conferences. He was the guest co-editor of several previous Special Issues of the Analog Integrated Circuits and Signal Processing Journal. One of the publications he co-authored in IEEE Transactions on Circuits and Sytems II-Analog and Digital Signal Processing was among the top cited papers listed in IEEE Circuits and Systems Society web page. He received the Research Excellence Award of Bogazici University Foundation in 2004. He served as the co-chair of Amplifiers and Comparators track in 50th IEEE Midwest-Newcas Joint Conference which is held in MontrealCanada as a track chair in the 52th IEEE Midwest Symposium held in Cancun-Mexico. His current research interests include analog circuits, active filters, analog signal processing applications, current-mode and MOS only circuits. He is the author or co-author of about 200 papers published in scientific journals or conference proceedings and conducts review in numerous journals including Analog Integrated Circuits and Signal Processing, IEEE CAS-I, IEEE CAS-II, International Journal of Electronics, International Journal of Circuit Theory and Applications, IEE Proceedings Pt.G, ETRI Journal and several others. Oguzhan Cicekoglu is a member of the IEEE and is the Associate Editor of International Journal of Electronics.

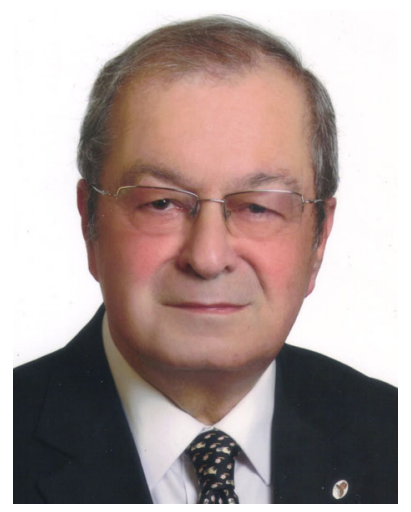

H. H. Kuntman received his B.Sc., M.Sc. and Ph.D. degrees from Istanbul Technical University in 1974, 1977 and 1982, respectively. In 1974, he joined the Electronics and Communication Engineering Department of Istanbul Technical University. Since 1993, he is a professor of electronics in the same department (retired, April 2016). His research interest includes design of electronic circuits, modeling of electron devices and electronic systems, active filters, design of analog IC topologies. Dr. Kuntman has authored many publications on modelling and simulation of electron devices and electronic circuits for computer-aided design, analog VLSI design and active circuit design. He is the author or the coauthor of 129 journal papers published or accepted for publishing in international journals, 185 conference papers presented or accepted for presentation in international conferences, 161 Turkish conference papers presented in national conferences and 10 books related to the above mentioned area. 